\title{
Working memory impairment in multiple sclerosis relapsing-remitting patients with episodic memory deficits
}

\author{
Simone Freitas Fuso' ${ }^{1}$, Dagoberto Callegaro², \\ Sabine Pompéia, ${ }^{3}$ Orlando F.A. Bueno ${ }^{4}$
}

\begin{abstract}
Episodic memory is impaired in multiple sclerosis (MS) patients, possibly because of deficits in working memory (WM) functioning. If so, WM alterations should necessarily be found in patients with episodic memory deficits, but this has not yet been demonstrated. In this study we aimed at determining whether episodic memory deficits in relapsing-remitting MS are found in conjunction with impaired WM. We evaluated $32 \mathrm{MS}$ patients and 32 matched healthy controls. Nineteen of the 32 patients had episodic memory impairment, and as a group only these individuals showed deficits in WM capacity, which may lead to difficulty in encoding, and/or retrieving information from episodic memory.

Key words: memory, multiple sclerosis, memory short-term, neuropsychological tests, cognition.
\end{abstract}

Prejuízo de memória operacional em pacientes com esclerose múltipla recorrenteremitente com déficits de memória episódica

\section{RESUMO}

Pacientes com esclerose múltipla (EM) apresentam prejuízo de memória episódica possivelmente em decorrência de um déficit no funcionamento da memória operacional (MO). Se assim fosse, alterações de MO seriam necessariamente encontradas em pacientes com déficit de memória episódica, mas isto ainda não foi demonstrado. Neste estudo tivemos como objetivo determinar se déficits de memória episódica em pacientes com EM recorrente-remitente são encontrados em associação com prejuízo de MO. Avaliamos 32 pacientes com EM pareados com 32 voluntários saudáveis. Dezenove dos 32 pacientes apresentaram prejuízo de memória episódica, e como grupo, somente estes indivíduos apresentaram déficit na capacidade de $\mathrm{MO}$, o que deve resultar na dificuldade de codificar, e /ou recuperar informações da memória episódica.

Palavras-chave: memória, esclerose múltipla, memória de curto-prazo, testes neuropsicológicos, cognição.

\section{Correspondence \\ Sabine Pompéia \\ Rua Napoleão de Barros 925 \\ 04024-002 São Paulo SP - Brasil \\ E-mail: spompeia@gmail.com \\ Financial support \\ Associação Fundo Incentivo à \\ Psicofarmacologia (AFIP) and Fundação de Amparo à Pesquisa do Estado de São Paulo (FAPESP) Simone Freitas Fuso received MSc grant from FAPESP, \# 01/06699-9}

Received 14 July 2009

Received in final form 24 September 2009 Accepted 16 October 2009
It is estimated that approximately half of multiple sclerosis (MS) patients exhibit cognitive impairment that can be detected from early phases of the disease ${ }^{1}$. Among the most commonly cited affected domains are episodic ${ }^{2-4}$ and working memory (WM) ${ }^{5,6}$. WM can be understood as the limited capacity to store and manipulate information for a short peri- od of time ${ }^{7}$. This system has been slightly altered since its proposal and is today comprised of the following components or subsystems ${ }^{7}$ : the central executive that is thought of as a limited-attentional component which coordinates, controls and manipulates information stored in other limited capacity subsystems of WM, the phonological loop and the visuospatial sketch-

${ }^{1} \mathrm{PhD}$, Department of Psychobiology, Federal University of São Paulo (UNIFESP), São Paulo SP, Brazil; ${ }^{2} \mathrm{MD}$, PhD, Center for Myelin Disorders of Clinical Hospital - Department of Neurology, University of São Paulo, São Paulo SP, Brazil; ${ }^{3 P h D, ~ A f f i l i a t e ~}$ Professor, Department of Psychobiology, Federal Universidade of São Paulo (UNIFESP), São Paulo SP, Brazil; ${ }^{4}$ PhD, Adjunct Professor, Department of Psychobiology, Federal University of São Paulo (UNIFESP), São Paulo SP, Brazil 
pad, which store verbal and visuospatial information, respectively; and the episodic buffer component, which provides temporary storage of information held in a multimodal code, which is capable of binding into a unity information stored in WM and long-term memory ${ }^{7}$. The central executive plays an important role in coordinating the transfer of information to and from WM to longterm memory through the episodic buffer ${ }^{7}$, so impairment in either of these WM components could determine episodic memory deficits. Both these WM subsystems are intricately related to the concept of "WM span" and "WM capacity", or the efficiency of executive functions in maintaining task-relevant representations in WM in the presence of distracting irrelevant information ${ }^{8}$. It has been suggested that alterations in WM capacity underlie the impairment in new episodic learning found in secondary progressive ${ }^{5}$, and depressed ${ }^{9} \mathrm{MS}$ patients, but not in non-depressed patients in earlier phases of the disease. More specifically, it is thought that this effect may stems from impaired deployment of executive strategies involved in WM capacity9. However, it is still unclear in what way and to what extent WM is responsible for episodic memory alteration in MS, especially in relapsingremitting patients. This is not surprising if one considers that only a subgroup of these patients have memory problems, so deficits in these domains are bound to be masked and/or distorted in studies that include individuals who are heterogeneous in terms of memory problems.

If WM alterations, considering its executive and episodic buffer components, were in fact responsible for episodic memory deficits in MS, then episodic memory impairment should be observed only in patients who show WM alterations. This has never been experimentally shown. Such a finding would point to the need to study subgroups of MS patients that are homogenous in term of memory impairment so that further steps can be taken to determine whether, in what way, and to what extent episodic memory problems result from altered encoding and/or retrieval processes that involve WM. This, in turn, may help in the development of specific rehabilitation practices for these patients.

In the present study we investigated memory performance of relapsing-remitting MS patients and healthy matched controls. We separated the patients into subgroups depending on the presence of clear episodic memory impairment. We then determined whether these subgroups of patients differed in their pattern of WM performance. Because several authors have asserted that memory deficits of MS patients are due to the need for more time to process information efficiently ${ }^{10-12}$, the WM tasks used here were carried out at different speeds. Our aim was to determine whether WM alterations are found in conjunction with episodic memory impairment and if manipulations in speed of information processing would change the pattern of results in relapsing-remitting patients.

\section{METHOD}

\section{Participants}

We evaluated 32 relapsing-remitting MS patients (26 female and 6 male) classified according to Lublin and Reingold ${ }^{13}$, diagnosed using the criteria proposed by McDonald et al. ${ }^{14}$, recruited from the Neurological Clinic at the Clinical Hospital of the School of Medicine, University of São Paulo (USP). They had no history of psychiatric or other neurological disorders, drug abuse or other medical complications. Exclusion criteria were use of glucocorticoids within the last four weeks, and presence of symptom exacerbation and/or clinical manifestations other than relapsing-remitting MS.

Thirty-two healthy volunteers with no history of neurological or psychiatric disorders, drug abuse or other medical complications were matched to MS patients in terms of age, gender, and years of schooling.

All subjects provided written informed consent to take part in the study, which was approved by local Ethics Committees (USP, UNIFESP).

Patients were distributed into two groups according to their scores in the delayed episodic memory measures employed (see description of these tests below): MS impaired, who had scores more than one standard deviation below the control group mean on at least two out of the three delayed episodic memory tasks, and MS non-impaired, a group comprised of the remaining MS patients. Nineteen patients (16 females and 3 males) were included in the MS-impaired group and the remaining 13 in the MS - non-impaired group (10 females and 3 males).

One-way ANOVAs with group as factor (controls, MS impaired and MS non-impaired) showed no significant differences between groups in terms of age, years of education, premorbid intellectual abilities, mood (assessed through Beck Depression Inventory and State and Trait Anxiety), duration of illness and EDSS scores ${ }^{15}$. Data in terms of means and standard-deviations are represented in Table 1.

\section{Neuropsychological test battery}

The neuropsychological test battery included a measure of pre-morbid intellectual abilities (Vocabulary Subtest of the WAIS-R ${ }^{16}$ ), WM tests with different speed limits and classic measures of episodic memory.

\section{Episodic memory}

- Logical Memory from the Wechsler Memory Scale Revised (WMS-R) ${ }^{17}$ : Immediate (measure of the episodic buffer) and delayed (after $30 \mathrm{~min}$ ) recall (measure of epi- 
Table 1. Demographic and clinical characteristics of groups [mean (standard deviation)].

\begin{tabular}{|c|c|c|c|c|}
\hline & Control $(\mathrm{N}=32)$ & MS non-impaired $(\mathrm{N}=13)$ & MS impaired $(\mathrm{N}=19)$ & $\mathrm{p}$ \\
\hline Age & $37.18(9.19)$ & $36.73(8.08)$ & $39.76(7.75)$ & NS \\
\hline Years of education & $13.71(2.59)$ & $13.94(2.54)$ & $13.23(2.71)$ & NS \\
\hline Disease duration (years) & - & $10.73(5.92)$ & $10.76(5.91)$ & NS \\
\hline EDSS & - & $1.84(1.17)$ & $2.84(1.35)$ & NS \\
\hline Beck Depression Inventory & $11.07(11.06)$ & $7.66(6.72)$ & $9.74(6.24)$ & NS \\
\hline STAI - State & $39.38(13.03)$ & $39.41(11.22)$ & $40.84(6.04)$ & NS \\
\hline STAI - Trait & $37.24(13.90)$ & $39.75(9.20)$ & $43.89(11.30)$ & NS \\
\hline Vocabulary - WAIS-R & $10.09(2.67)$ & $11.23(2.38)$ & $8.73(2.42)$ & NS \\
\hline
\end{tabular}

MS: multiple sclerosis; EDSS: Expanded Disease Status Scale; STAI: State-Trait Anxiety Inventory; WAIS-R: Weschler Adult Intelligence Scale - Revised; N: number of subjects; NS: non significant.

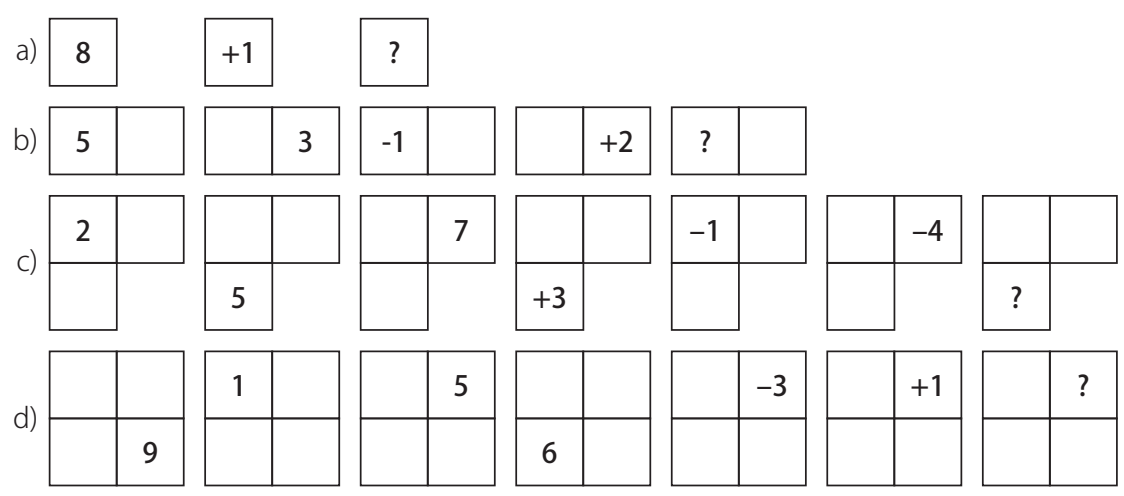

Fig 1. Example of the Operational Capacity Test. (a) 1 cell and 1 operation; correct response: 9; (b) 2 cells and 2 operations; correct response: 4; (c) 3 cells and 3 operations; correct response: 8; (d) 4 cells and 2 operations; correct response: 3 .

sodic memory) of prose were assessed. The score was the number of the idea units recalled.

- Visual Reproduction from the WMS- $\mathrm{R}^{17}$ : Immediate and delayed (after $30 \mathrm{~min}$ ) recall of a geometric drawings was evaluated. The score was the number of units reproduced.

- Rey Auditory-Verbal Learning Test (RAVLT $)^{18}$ : This task measures learning of a list of 15 nouns (List A) over 5 trials with immediate free-recalls after each trial. Subjects then learn another list ("interference") of 15 nouns (List B) that is presented once, followed by immediate free-recall, after which they must recall the first list again (recall after interference). A delayed recall (episodic memory measure) of the first list is then required after $30 \mathrm{~min}$, followed by a recognition test. The score is the number of words recalled in each immediate trial, delayed recall and recognition tests. False positives (words recognizes as seen that were not on the lists) were also computed.

\section{WM and information processing speed}

- Paced Auditory Serial Addition Test (PASAT) ${ }^{19}$ : used to measure WM information processing at different speeds. Participants hear a list of randomized single digits presented in 4 trials of 61 digits at 4 speeds of presentation (one digit every $1.2 \mathrm{~s}, 1.6 \mathrm{~s}, 2.0 \mathrm{~s}$ and $2.4 \mathrm{~s}$ ). Subjects are required to add each digit to the one immediately preceding it. Performance is evaluated by calculating the number of correct responses on each trial. This is the most used neuropsychological test in people with multiple sclerosis.

- Operational Capacity Test (adapted from Archibald and Fisk ${ }^{5}$, Fig 1): This task assesses WM capacity. It involves maintaining digits and their locations in mind while performing one to four calculations. In addition, the speed of information processing is manipulated [inter stimulus interval (ISI) of $2.4 \mathrm{~s}$ or $1.2 \mathrm{~s}$ ]. The task begins with the presentation of a single digit in a single cell. After it disappears, another digit is presented together with a plus or minus sign. This information disappears and is followed by the presentation of a question mark. The subject's task is to type in the result of the calculation. There is no time limit for responses. This is repeated 4 times, with presentation times of $1 \mathrm{~s}$ and ISI of $2.4 \mathrm{~s}$. Equivalent tasks then follow in which two, then three and finally 4 mathematical operations must be conducted (e.g. for four operations: $1+2-3+4+1$ ), each new digit, plus operation sign, presented for the same amount of time at the same 
Table 2. Neuropsychological performance of groups [mean (standard deviation)].

\begin{tabular}{lccc}
\hline Test & Control (N=32) & MS non-impaired (N=13) & MS impaired (N=19) \\
\hline Logical memory I & $30.15(6.99)$ & $29.00(6.67)$ & $21.89(7.48)^{* \#}$ \\
Logical memory II & $27.28(6.59)$ & $25.76(7.08)$ & $16.73(9.38)^{* \#}$ \\
Visual Reproduction I & $36.75(3.28)$ & $37.23(4.26)$ & $33.00(6.44)^{* \#}$ \\
Visual Reproduction II & $33.40(5.00)$ & $34.76(5.10)$ & $26.57(8.08)^{* \#}$ \\
RAVLT & & & \\
$\quad$ I & $7.15(1.76)$ & $6.69(2.21)$ & $6.10(1.33)^{*}$ \\
$\quad$ II & $10.46(1.62)$ & $9.69(1.80)$ & $8.89(2.02)^{* \#}$ \\
$\quad$ III & $12.56(1.84)$ & $11.38(1.98) *$ & $10.31(1.92)^{* \#}$ \\
$\quad$ IV & $13.15(1.29)$ & $12.69(1.65)$ & $10.63(1.98)^{* \#}$ \\
$\quad$ V & $13.62(1.43)$ & $13.23(1.16)$ & $11.31(2.00)^{* \#}$ \\
After interference & $12.81(1.82)$ & $11.46(2.26)$ & $8.68(2.56)^{* \#}$ \\
After 30 min & $13.12(1.82)$ & $11.38(2.53)$ & $8.26(2.96)^{* \#}$ \\
Recognition & $14.68(0.93)$ & $14.46(0.88)$ & $13.63(1.77)^{* \#}$ \\
False positive & $0.12(0.42)$ & $0.23(0.60)$ & $0.63(0.60)^{* \#}$ \\
\hline
\end{tabular}

*Different from control; \#different from MS non-impaired (ps<0.05); RAVLT: Rey Auditory Verbal Learning Test.

ISI. Next, the same task is repeated now using 2, then 3 and finally 4 cells, the information being presented only in one cell at a time. The question mark, however, appears at the end of each trial in only one cell and results must refer to calculations performed with stimuli presented in that same cell. Subjects then conduct the same task with ISI of $1.2 \mathrm{~s}$. The digits, operations, question marks and cells in which information appear are randomly determined. Twelve test conditions were evaluated according to the number of cells: trials with 1 and 4 cells included 1 to 4 operations; trials with 2 and 3 cells included 1 and 4 operations only. Hence, in this last case (4 cells), subjects have to remember the minimum of 4 first digits presented, plus 1 operation, and the maximum of 4 digits, plus 4 operations (which appear in one or more cells). For each condition there were four trials, thus totaling 48 sequences for each ISI. Test scores were the number of mistakes in each condition. Subjects carried out 8 practice trials.

\section{Statistical analysis}

Performance of the three groups (MS impaired, MS non-impaired and controls) were compared using analysis of variance (ANOVA), followed by the Newman-Keuls post hoc test when significant effects were found. Factors will be detailed below. The significance level adopted was $\mathrm{p} \leq 0.05$. Variables and comparisons that are not cited below did not show significant effects.

\section{RESULTS} Neuropsychological tests performance (Table 2)
Episodic memory

- Logical memory: The two-way ANOVA showed a group effect $[\mathrm{F}(2.61)=10.92 ; \mathrm{p}<0.001]$, as well as a delay effect (immediate, delayed) $[\mathrm{F}(1.61)=55.29 ; \mathrm{p}<0.001]$, but no interaction. The post hoc analysis showed that the MS impaired group performed worse than the other two groups (ps $<0.001$ ), which did not differ. Immediate was better than delayed recall in all groups $(\mathrm{ps}<0.001)$ at a proportional level.

- Visual reproduction: The ANOVA revealed the same results as above [group effect $\mathrm{F}(2.61)=49.82 ; \mathrm{p}<0.001$; delay effect $F(1.61)=53.74 ; \mathrm{p}<0.001]$.

- RAVLT: For immediate recall, an interaction between group and trial $[\mathrm{F}(8.244)=2.19 ; \mathrm{p}<0.03]$ was observed. Post hoc analysis indicated that on trial I, performance of MS impaired subjects did not differ from that of the MS non-impaired, but was worse than that of the control group $(\mathrm{p}<0.02)$, which was equivalent to the MS non-impaired patients. At trials II, III, IV and V the MS impaired group recalled fewer words than both other groups $(\mathrm{ps}<0.04)$. The MS non-impaired group showed worse performance than the control group only on trial III ( $\mathrm{p}=0.002$ ), but not on the following trial, suggesting that this was a type I error. However, all groups showed learning effects, having been able to remember more words after five readings ( $\mathrm{ps}<0.001)$.

One-way ANOVAs for data of the post-B trial (after interference) $[\mathrm{F}(2.58)=19.80, \mathrm{p}<0.0001]$, delayed recall $[F(2.58)=23.28 ; \mathrm{p}<0.0001]$ and recognition $[\mathrm{F}(2.58)=4.17$; $\mathrm{p}<0.03]$ revealed group effects, MS impaired patients having had worse performance than the other groups $(\mathrm{ps}<0.05)$. MS impaired subjects still had worse performance $[\mathrm{F}(2.58)=6.25, \mathrm{p}<0.04]$ than the other groups $(\mathrm{ps}<0.02)$ when the number of recognized words was cor- 
rected for the number of learned words after 5 trials, dividing the number of words recognized by the number of words recalled in the $5^{\text {th }}$ trial.

WM and information processing speed

- PASAT (Fig 2): The ANOVA revealed significant differences between groups $[\mathrm{F}(2.61)=4.15 ; \mathrm{p}=0.02]$, and speed $[F(3.183)=79.56 ; p<0.001]$, but no interaction. Only the MS impaired patients had lower scores in relation to both other groups ( $\mathrm{ps} \leq 0.05)$, and the faster the presentation speed, the worse all groups performed ( $\mathrm{ps}<0.003)$.

- Operational capacity test (Fig 3): Four three-way ANOVAs were performed following Archibald and Fisk ${ }^{5}$ to compare groups in terms of the number of mistakes committed in this task. In none of them did speed interact with group. Also, in all cases performance at higher speed and with more operations/cells led to lower performance $(\mathrm{ps}<0.05)$. There was no group effect in the first ANOVA that was carried out for the trials in which there was only one cell [factors were groups, speed (1.2 and 2.4 s ISI) and number of operations (1 to 4)].

A similar ANOVA as the one above was performed for 4 cells (also with 1 to 4 operations). In this case, we found an interaction between groups and number of operations $[\mathrm{F}(6.183)=2.22 ; \mathrm{p}<0.05]$. Post hoc tests showed specific group differences in that both MS groups had

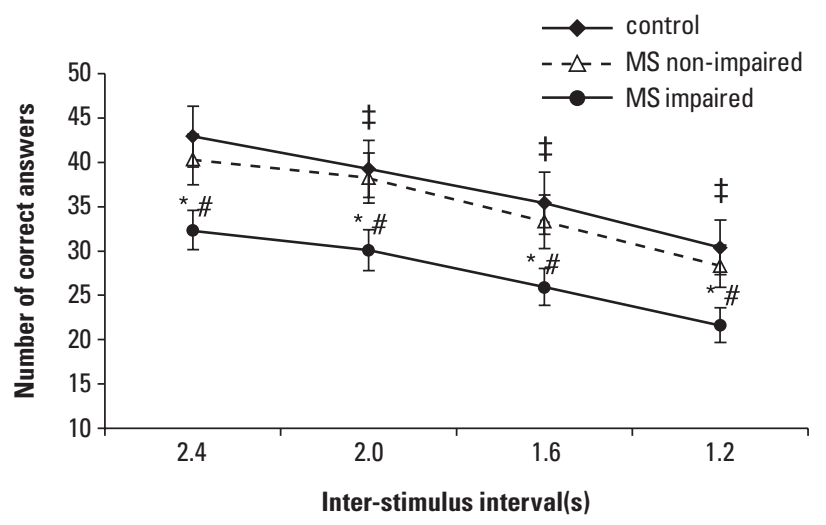

Fig 2. Performance on the PASAT of the three groups [mean (standard errors)]. *Different from control group; \# Different from MS non-impaired; \# Different from longer ISIs (ps<0.05); PASAT: Paced Auditory Serial Addition Test.

more difficulty when there were 4 in relation to 3 operations (ps<0.03), an effect not observed for the control group, the only measure to differentiate control and MS non impaired participants, indicating that this measure is particularly sensitive to MS. Also, the MS impaired patients exhibited worse performance than the other groups, having made more mistakes when conducting 2 operations in relation to $1(\mathrm{p}<0.02)$.

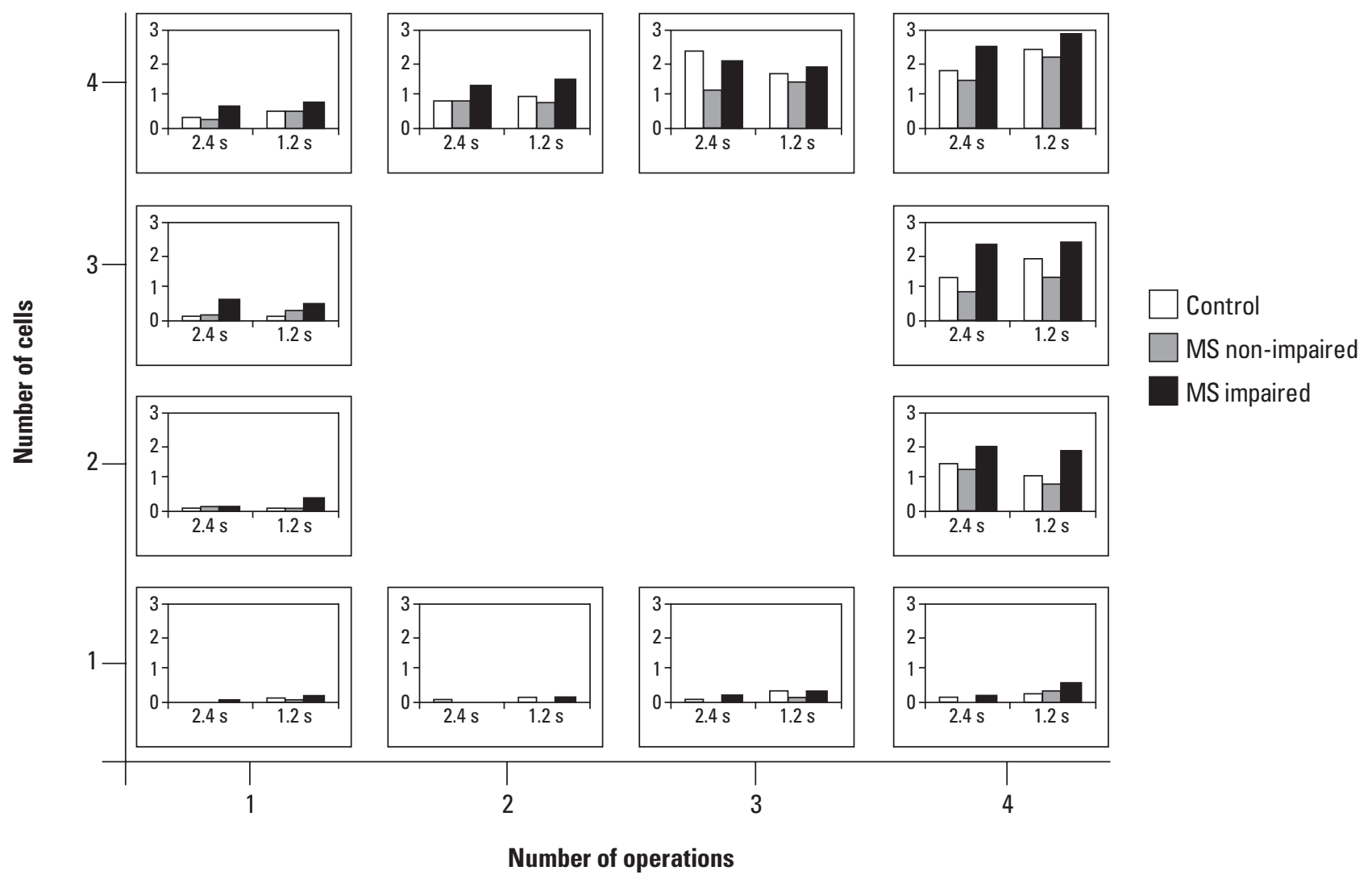

Fig 3. Number of errors in each group in the Operational Capacity Test (ISI 2.4 and 1.2 seconds) according to number of cells and number of operations. 
Two other three-way ANOVAs were carried out for the trials in which only one or 4 operations were involved. They had group, speed (1.2 and 2.4 s ISI) and cells (1 to 4) as factors. Only the ANOVA with 4 operations showed a group effect $[\mathrm{F}(2.61)=4.74 ; \mathrm{p}<0.02]$, the MS impaired patients having performed worse than the other groups (ps $<0.04)$, which did not differ .

\section{DISCUSSION}

In the present study we showed that MS relapsingremitting patients were heterogeneous in terms of performance in delayed episodic memory tasks, despite being equivalent in terms of their clinical status and demographic characteristics. This enabled the differentiation of subjects into those who did and did not exhibit clear impairment in this specific cognitive domain. On this basis, nineteen out of 32 patients had performance that was below mean minus one standard deviation in comparison to controls in at least two out of three verbal and visual episodic memory tasks (MS impaired), corroborating cognitive (episodic memory) deficit in approximately half of MS patients ${ }^{1}$. Despite subjects in all groups having been capable of learning verbal information as measured by the RAVLT, only the MS impaired patient group showed lower performance, in agreement with previous reports of learning deficits in $\mathrm{MS}^{4,20}$, and also more susceptibility to interference (post-B stage and after $30 \mathrm{~min}$ at RAVLT) as observed by Rao et al. ${ }^{21}$.

In addition to this acquisition deficit that is often described in $\mathrm{MS}^{4,10}$, in the recognition stage of the RAVLT, the MS impaired group had more false-positives and lower rates of recognition when compared to the other two groups. This confirms consolidation and/or retrieval difficulties in these patients ${ }^{22,23}$, despite others studies having found no change in this type of measure ${ }^{4,20}$. It is possible that this disagreement in recognition data may be accounted for by the use of heterogeneous groups of patients in terms of episodic memory impairment, which would lead to a large variability in performance from study to study.

In the PASAT test only the MS impaired group made more mistakes, indicating a commonly found WM deficit in this population ${ }^{1,24,25}$. Results in the Operational Capacity Test, a measure of WM capacity, also showed that the MS impaired subjects made more errors when number of cells and, especially, of operations, increased. Archibald and Fisk ${ }^{5}$ reported similar findings but only in secondaryprogressive MS patients. Had they adopted the homogenous memory-impaired group approach they could have found similar results as those reported here in relapsingremitting participants. WM capacity deficits were also found in depressed MS patients ${ }^{9}$ but such a mood alteration could not account for the present data since none of the patients had scores in the questionnaire that was indicative of depression. Furthermore, this impairment in the functioning of the episodic buffer can also be inferred in the MS impaired patients because their immediate recall of prose (logical memory).

The way in which speed and WM deficits relate in MS is not clear ${ }^{11}$. In the present study we believe that the data cannot be explained solely on the basis that speed was affected since speed did not interact with group in any measure. Should processing speed be the only causal factor for MS memory deficits, the impairment found here in immediate recall of the RAVLT and logical memory tests, in which information is delivered at a slow rate, would not be expected. Interestingly, healthy subjects with low WM capacity have been shown to recall fewer items in freerecall long-term memory tasks, recall at slower rates and make more intrusion errors than those with high WM capacity, which is consistent with the idea that they present problems in WM related to inhibition and/or stimulus discrimination ${ }^{26}$. Hence, it is possible that the WM capacity deficits shown here in some MS patients could explain widespread reports of impairment in processing speed, episodic memory and susceptibility to interference in these patients.

In theoretical terms the fact that WM deficits accompany episodic memory impairment in MS should not come as a surprise. The executive component of WM, and/or the episodic buffer, both related to the concept of WM capacity, have a prominent role in episodic memory acquisition and retrieval ${ }^{7,27}$ and are impaired in MS patients $^{5,9}$. This, however, has not been shown before in relapsing-remitting MS patients, in which cognitive impairment is not as pronounced as in further stages of the disease and is, therefore, more difficult to detect. We have shown here that in order to do so it is important to adopt the subgroup approach and focus on the deficits observed only in the subgroup of patients who have memory problems in order to decrease the variability of the data. This approach may aid in the better understanding of the relations between working and long-term memory in MS, which is crucial for the development of helpful rehabilitation measures.

Unfortunately the present study was not designed to determine which areas of the brain are altered to produce the cognitive impairment that was found. In this respect, recent findings have shown that MS, as a white matter disease, can lead to cognitive dysfunction that may be better explained by a disconnection between distant cerebral regions than by primary damage of these regions themselves. In effect, Dineen et al. ${ }^{28}$ showed that functionally relevant tract injury, evaluated using diffusion tensor magnetic resonance imaging, may underlie cognitive dysfunction in patients with MS in tasks of sustained atten- 
tion, working memory and processing speed, visual working memory and verbal learning and recall. The authors also caution, however, that these tract alterations may involve possible compensatory processing pathways in MS. Either way, the possibility of using such techniques to investigate connectivity in key systems in the brain necessary for cognitive processing may come to be a physiological marker that may explain the distinct pattern of performance of MS patients with and without memory deficits. If used at the onset of the disease, such studies may also enable the determination of which patients are likely to develop memory problems as the disease progresses.

\section{REFERENCES}

1. Amato MP, Zipoli V, Portaccio E. Cognitive changes in multiple sclerosis. Exp Rev Neurother 2008; 8:1585-1596.

2. Andrade VM, Bueno OFA, Oliveira MGM, Oliveira EML, Miranda MC. Cognitive profile of patients with relapsing remitting multiple sclerosis. Arq Neuropsiquiatr 1999:57:775-783.

3. Rao SM. Neuropsychology of multiple sclerosis: a critical review. J Clin Exp Neuropsychol 1986;8:503-542.

4. Thornton AE, Raz N, Tucke KA. Memory in multiple sclerosis: contextual encoding deficits. J Internat Neuropsychol Soc 2002;8:395-409.

5. Archibald CJ, Fisk JD. Information processing efficiency in patients with multiple sclerosis. J Clin Exp Neuropsychol 2000;22:686-701.

6. Lengenfelder J, Bryant D, Diamond BJ, Kalmar JH, Moore NB, DeLuca J. Processing speed interacts with working memory efficiency in multiple sclerosis. Arch Clin Neuropsychol 2006;21:229-238.

7. Baddeley AD. Working Memory, Thought, and Action (Oxford Psychology Series). Oxford: Oxford University Press, 2007.

8. Engle RW, Tuholski SW, Laughlin JE, Conway AR. Working memory, short term memory and general fluid intelligence: a latent variable approach. J Exp Psychol 1999;128:309-331.

9. Arnett PA, Higginson Cl, Voss WD, Bender WI, Wurst JM, Tippin JM. Depression in multiple sclerosis: relationship to working memory capacity. Neuropsychology 1999;13:546-556.

10. Litvan I, Grafman J, Vendrell P, et al. Multiple memory deficits in patients with multiple sclerosis. Exploring the working memory system. Arch Neurol 1988; 45:607-610.
11. DeLuca J, Chelune GJ, Tulsky DS, Lengenfelder J, Chiaravalloti ND. Is speed of processing or working memory the primary information processing deficit in multiple sclerosis? J Clin Expl Neuropsychol 2004;26:550-562.

12. Demaree HA, DeLuca J, Gaudino EA, Diamond BJ. Speed of information processing as a key deficit in multiple sclerosis: implications for rehabilitation. J Neurol Neurosurg Psychiatry 1999;67:661-663.

13. Lublin FD, Reingold SC. Defining the clinical course of multiple sclerosis: results of an international survey. National Multiple Sclerosis Society (USA). Advisory Committee on Clinical Trials of New Agents in Multiple Sclerosis. Neurology 1996;46:907-911.

14. McDonald WI, Compston A, Edan G, et al. Recommended diagnostic criteria for multiple sclerosis: guidelines from the International Panel on the diagnosis of multiple sclerosis. Ann Neurol 2001;50:121-127.

15. Kurtzke JF. Rating neurologic impairment in multiple sclerosis: an expanded disability status scale (EDSS). Neurology 1983;33:1444-1452.

16. Wechsler D. Wechsler Memory Scale-Revised manual. San Antonio, TX, The Psychological Corporation, 1987.

17. Wechsler D. Manual for the Wechsler Adult Intelligence Scale-Revised. New York, Psychological Corporation, 1981.

18. Rey A. Léxamen clinique en psychologie. Paris, Presse Universitaire de France, 1958.

19. Gronwall DM. Paced auditory serial-addition task: a measure of recovery from concussion. Percep Motor Skills 1977;44:367-373.

20. Rao SM, Leo GJ, St Aubin-Faubert P. On the nature of memory disturbance in multiple sclerosis. J Clin Expl Neuropsychol 1989;11:699-712.

21. Rao SM, Hammeke TA, McQuillen MP, Khatri BO, Lloyd D. Memory disturbance in chronic progressive multiple sclerosis. Arch Neurol 1984;41:625-631.

22. Bobholz JA, Rao SM, Lobeck L, et al. fMRI study of episodic memory in relapsingremitting MS: correlation with T2 lesion volume. Neurology 2006;67:1640-1645.

23. Sicotte NL, Kern KC, Giesser BS, et al. Regional hippocampal atrophy in multiple sclerosis. Brain 2008; 131:1134-1141.

24. Rosti E, Hämäläinen P, Koivisto K, Hokkanen L. PASAT in detecting cognitive impairment in relapsing-remitting MS. Applyed Neuropsychol 2007;14:101-112.

25. Grazioli E, Yeh AE, Benedict RHB, Parrish J, Weinstock-Guttman B. Cognitive dysfunction in MS: bridging the gap between neurocognitive deficits, neuropsychological batteries and MRI. Future Neurol 2008;3:49-59.

26. Unswoth N. Individual differences in working memory capacity and episodic retrieval: examining the dynamics of delayed and continuous distractor free recall. J Exp Psychol: Lear, Mem Cogn 2007;33:1020-1034.

27. Baddeley AD. The episodic buffer: a new component of working memory? Trends Cogn Sci 2000;4:417-423.

28. Dineen RA, Vilisaar J, Hlinka J, et al. Disconnection as a mechanism for cognitive dysfuncion in multiple sclerosis. Brain 2009;132:239-249. 